\title{
In vitro perforation of human epithelial carcinoma cell with antibody-conjugated biodegradable microspheres illuminated by a single 80 femtosecond near-infrared laser pulse
}

\author{
This article was published in the following Dove Press journal: \\ International Journal of Nanomedicine \\ 26 May 2012 \\ Number of times this article has been viewed
}

\section{Mitsuhiro Terakawa \\ Yasuyuki Tsunoi \\ Tatsuki Mitsuhashi \\ Department of Electronics and Electrical Engineering, Keio University, Yokohama, Kanagawa, Japan}

Correspondence: Mitsuhiro Terakawa Department of Electronics and Electrical Engineering, Keio University, 3-I4-I

Hiyoshi, Kohoku-ku, Yokohama,

Kanagawa 223-8522, Japan

Tel +8I 45566 I737

Fax $+8 \mid 45566 I 529$

Email terakawa@elec.keio.ac.jp
Abstract: Pulsed laser interaction with small metallic and dielectric particles has been receiving attention as a method of drug delivery to many cells. However, most of the particles are attended by many risks, which are mainly dependent upon particle size. Unlike other widely used particles, biodegradable particles have advantages of being broken down and eliminated by innate metabolic processes. In this paper, the perforation of cell membrane by a focused spot with transparent biodegradable microspheres excited by a single $800 \mathrm{~nm}, 80 \mathrm{fs}$ laser pulse is demonstrated. A polylactic acid (PLA) sphere, a biodegradable polymer, was used. Fluorescein isothiocyanate (FITC)-dextran and short interfering RNA were delivered into many human epithelial carcinoma cells (A431 cells) by applying a single $80 \mathrm{fs}$ laser pulse in the presence of antibody-conjugated PLA microspheres. The focused intensity was also simulated by the three-dimensional finite-difference time-domain method. Perforation by biodegradable spheres compared with other particles has the potential to be a much safer phototherapy and drug delivery method for patients. The present method can open a new avenue, which is considered an efficient adherent for the selective perforation of cells which express the specific antigen on the cell membrane.

Keywords: femtosecond laser, drug delivery, transfection, biodegradable polymer

\section{Introduction}

Recent advances in nano/microparticle technology have accelerated the application of these particles in biomedicine. Various promising and potential applications of these particles have been reported, including tissue engineering, ${ }_{1}^{1}$ diagnostics, ${ }^{2}$ cancer therapy, ${ }^{3}$ and drug delivery. ${ }^{4,5}$ However, many papers on the evaluation of risks in the use of the particles for biomedical applications are reported. Studies have reported nanoparticle-induced inflammation, effects on immunological systems, prethrombosis, and genotoxicity, which are dependent on particle size. ${ }^{6}$ Particles that may induce toxic effects at the nanoscale include gold, ${ }^{7,8}$ silver, ${ }^{9}$ titanium dioxide, ${ }^{10}$ and carbon black particles. ${ }^{11}$ Unlike the above particles, biodegradable particles have the advantage of degradation and elimination by innate metabolic processes. Biodegradable polymers have been widely used for sutures and bone fracture fixation materials in patients because of their degradation and nontoxic properties, and therefore biodegradable polymers have recently received considerable attention for use in drug delivery. ${ }^{12,13}$

There is a growing interest in laser interaction with particles for biomedical applications. Laser-mediated transfection is a promising nonviral method for spatially targeted 
therapy because of the high spatial controllability of laser pulsed energy delivery. Moreover, catheter-based transfection may also come into practical use because laser energy can be transmitted through an optical fiber. ${ }^{14}$ Laser irradiation to the antibody-conjugated particles which are selectively bound to targeted cells realizes tumor detection, ${ }^{15}$ photothermal therapy, ${ }^{3,16}$ and drug delivery. ${ }^{17,18}$ The use of a femtosecond laser with gold nanoparticles for the cell membrane perforation has also been reported. ${ }^{19-21}$ In this method, collective free electron oscillation (surface plasmon) inside the gold particle generates a highly enhanced near field, resulting in the generation of cavitation bubbles and shock waves in the close vicinity of the cell membrane. The use of carbon black nanoparticles as an optical absorber for initiating carbon-steam reactions has also perforated cell membranes. ${ }^{22}$ These methods realize the membrane perforation of many cells by a single laser pulse treatment. However, the above concerns related to nanoparticle-induced cytotoxicity still remain unsolved.

Recently, cell membrane perforation by a focused optical far field generated by many dielectric microspheres excited by a single femtosecond laser pulse has been reported. ${ }^{23}$ Fluorescent molecules and small interfering RNA (siRNA) were delivered into many cells in a large irradiated area by a single $80 \mathrm{fs}$ laser pulse in the presence of antibody-conjugated polystyrene (PS) spheres. The transparent sphere works as a microlens, ${ }^{24}$ and the cell membrane under the sphere can be perforated by a focused optical field. This method has an advantage in the high throughput in which many cells could be treated by laser scanning method.

In this study, the in vitro cell membrane perforation is demonstrated by using a biodegradable microsphere, instead of PS sphere, excited by an $800 \mathrm{~nm}$ femtosecond laser pulse to direct the method towards a much safer phototherapy and drug delivery outcome for patients. This process is based upon a single-shot femtosecond laser illumination to optically transparent polylactic acid (PLA) microspheres being conjugated to the cell membrane for perforation. PLA is a typical biodegradable polymer which can be broken down in biological tissue within a few months. ${ }^{25}$

\section{Materials and methods}

\section{Simulation system and procedure}

The enhanced optical field under the PLA sphere in water was calculated by the three-dimensional (3D) finite-difference time-domain (FDTD) method. The simulation system consists of a PLA sphere $(n=1.45)$ in water $(n=1.326)$. A plane laser wave is incident to the sphere with the wave vector in the $\mathrm{z}$ direction. The incident wave of $800 \mathrm{~nm}$ in wavelength is linearly polarized along the $\mathrm{x}$-axis. The enhanced optical field was simulated around the PLA sphere of $250,500,1000$, and $2000 \mathrm{~nm}$ in diameter.

\section{Cell culture}

Human epithelial carcinoma cells (A431 cells) were obtained from RIKEN BRC (Tsukuba, Japan). The cells were cultured as a monolayer in Dulbecco's Modified Eagle's Medium supplemented with 10\% fetal bovine serum under a humidified atmosphere of $95 \%$ air and $5 \% \mathrm{CO}_{2}$ at $37^{\circ} \mathrm{C}$. The cells were harvested and seeded in glass-bottom culture dishes for the experiments.

\section{Cell membrane perforation}

Figure 1 shows a conceptual diagram of dielectric spheremediated perforation using femtosecond laser. Spherical protein A conjugated PLA spheres, which have a diameter of $2000 \mathrm{~nm}$, were mixed with anti-epidermal growth factor receptor (EGFR) mouse monoclonal antibody (Thermo Fisher Scientific, Fremont, CA). The anti-EGFR antibody can

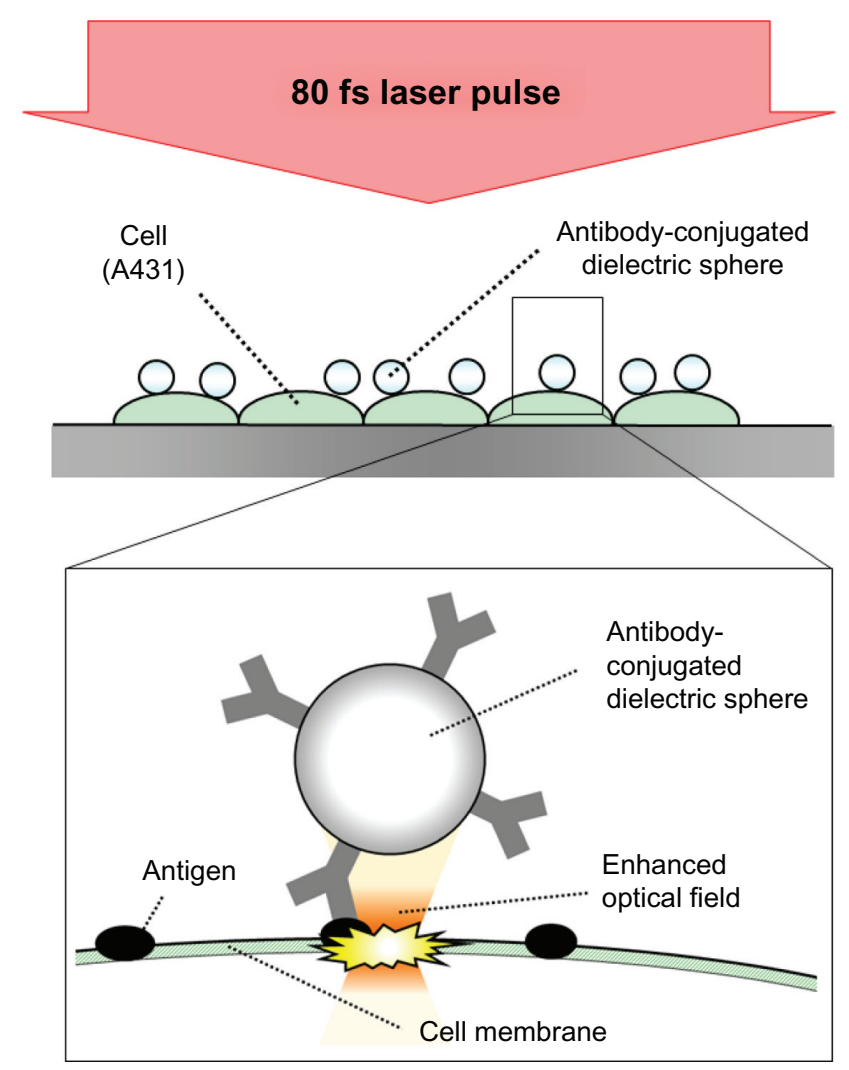

Figure I Conceptual diagram of dielectric sphere-mediated perforation using femtosecond (fs) laser.

Notes: Biodegradable spheres are conjugated to cell membrane via antigenantibody interaction. Femtosecond laser illumination to the spheres generates a strongly enhanced optical field under the sphere for perforation. 
be employed to target overexpressed EGFR on A431 cells. The mixture was stirred for 25 minutes at room temperature. After the removal of unbound antibody by centrifugation for 10 minutes at 10,000 rpm, the conjugated PLA microspheres were resuspended in phosphate-buffered saline (PBS) and added to A431 cells. The cells were incubated for 40 minutes at $37^{\circ} \mathrm{C}$ and washed three times with PBS to remove the unbound microspheres. The uptake of the microspheres by the cells was not observed in the incubation time of 40 minutes in this study.

A Ti:sapphire chirped pulse amplification laser system (Libra, Coherent, Santa Clara, CA), which generates 80 femtosecond (fs) laser pulses at $800 \mathrm{~nm}$ central wavelength, was used in the experiments. Photons at wavelength of $800 \mathrm{~nm}$ can penetrate deeply into tissue due to the low optical absorption and relatively low scattering coefficients. The laser beam was weakly focused by using a plano-convex lens $(f=200 \mathrm{~mm})$ to a laser spot size of $300 \mu \mathrm{m}$. The cells were illuminated by a single shot of the linearly polarized laser from the top side of the cells. The fluorescein isothiocyanate (FITC)-dextran (20 kDa, Sigma, St Louis, MO) and Alexa Fluor-labeled siRNA (15.5 kDa, Qiagen, Chatsworth, CA) were used for the evaluation of the permeabilization. The FITC-dextran solution $(0.1 \mathrm{mM})$ or the siRNA solution $(5 \mu \mathrm{M})$ was added to the cells just before the 80 fs laser illumination. Two minutes after the illumination, the solution was removed and the cells were washed three times with PBS. Fluorescent molecules uptaken by the cells were observed by using a fluorescence microscope (Eclipse Ti-E, Nikon, Tokyo, Japan). The cell viability was evaluated by a trypan blue dye exclusion test.

\section{Results and discussion}

Figure 2 shows the optical intensity distribution at $800 \mathrm{~nm}$ wavelength under the PLA microsphere calculated by the $3 \mathrm{D}$ FDTD method. The optical near field in the vicinity of the PLA sphere with diameters of 250 and $500 \mathrm{~nm}$ is governed mainly by the Mie scattering process. The optical enhancement by the Mie scattering is basically dependent upon the size parameter $\alpha=2 \pi R / \lambda$, where $R$ is the sphere radius and $\lambda$ is the incident wavelength. The low enhancement factors obtained with sphere diameters of 250 and $500 \mathrm{~nm}$ are attributed to the off-resonant Mie scattering regime and the low refractive index difference between PLA sphere $(n=1.45)$ and water $(n=1.326)$ at $800 \mathrm{~nm}$ wavelength. ${ }^{24,26}$ The underlying physics for enhanced optical field under the sphere shifts from Mie resonance scattering domain to microlens effect with the increase of the sphere diameter. The enhancement factor obtained with the PLA sphere diameter of $1000 \mathrm{~nm}$ is 4.0 in relation to the incident optical intensity, while that obtained with the PS sphere of $1000 \mathrm{~nm}$ diameter is enhanced to be 8.4. ${ }^{23}$ The higher enhancement factor with the PS sphere is explained by the higher refractive index of the PS sphere $(n=1.577)$ compared with the PLA sphere. ${ }^{26}$ The PLA sphere of $2000 \mathrm{~nm}$ diameter mainly behaves as a microlens and the optical intensity is enhanced by a factor of 9.7 in relation to the incident optical intensity at $870 \mathrm{~nm}$ under the sphere (Figure 2D). Based on the optical intensity distribution, the spheres conjugate to the top surface of the cell work for the perforation, while those conjugate to the side surface may not. The full width at half maximums (FWHMs) on the $\mathrm{x}$ - and y-axes were 609 and $551 \mathrm{~nm}$, respectively, suggesting that the submicrometer pores may be formed on the cell membrane.

According to the calculated optical intensity, the PLA sphere of $2000 \mathrm{~nm}$ in diameter was used for the in vitro experiments.

Figure 3 shows a phase contrast image of the A431 cells and the PLA microspheres taken before the laser illumination. As can be seen in the figure, the spheres of $2000 \mathrm{~nm}$ diameter conjugated to the A431 cells, which are $40-50 \mu \mathrm{m}$ in size. The average number of spheres conjugated to the cell membrane is 51 .

Figure 4 shows fluorescence images (A and C) and phase contrast images (B and D) of the cells after the 80 fs laser illumination at the laser fluence of $1.06 \mathrm{~J} / \mathrm{cm}^{2}$, corresponding to the peak intensity of $1.29 \times 10^{14} \mathrm{~W} / \mathrm{cm}^{2}$ under the sphere. The corresponding incident energy to the fs laser illuminated area (300 $\mu \mathrm{m}$ in diameter) is $0.75 \mathrm{~mJ}$. Figure $4 \mathrm{~A}$ and $\mathrm{B}$ show experimental results obtained with the FITC-dextran, while Figure $4 \mathrm{C}$ and D show those obtained with the siRNA. The average number of cells in the fs laser illuminated area was 221. Many cells in the illuminated area showed fluorescence, demonstrating the increase in the cell membrane permeability. The average perforation efficiency, which was defined as the fraction of cells in the irradiated area that took up exogenous molecules, evaluated by using FITCdextran at this laser fluence, was $26.4 \% \pm 7.5 \%(\mathrm{~N}=5)$, while that evaluated by using siRNA was $34.9 \% \pm 6.5 \%$ $(\mathrm{N}=7)$. No statistically significant difference was observed in the perforation efficiencies with FITC-dextran and siRNA ( $P>0.05$ in nonparametric Mann-Whitney test). The perforation efficiency obtained by using PLA spheres is comparable to that shown in a previous study using PS sphere, ${ }^{23}$ demonstrating the effectiveness and applicability of biodegradable polymer for the perforation. As shown in Figure 2H, the PLA sphere of $2000 \mathrm{~nm}$ diameter works 


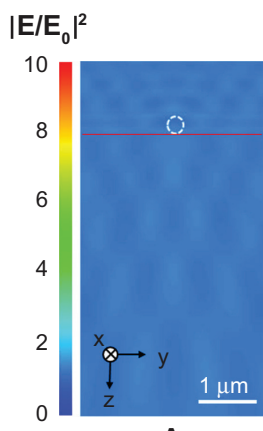

A

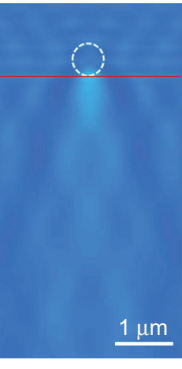

B

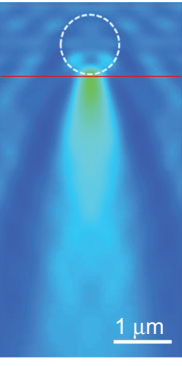

C

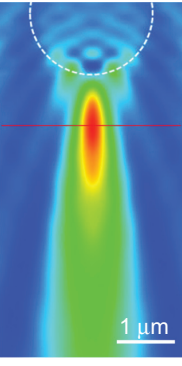

D

E

$\left|E / E_{0}\right|^{2}$

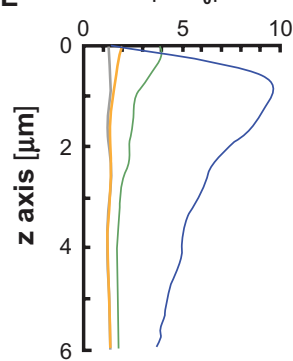

- $2 \mathrm{R}=0.25 \mu \mathrm{m}$

$2 \mathrm{R}=0.50 \mu \mathrm{m}$

$2 \mathrm{R}=1.00 \mu \mathrm{m}$

$2 \mathrm{R}=2.00 \mu \mathrm{m}$
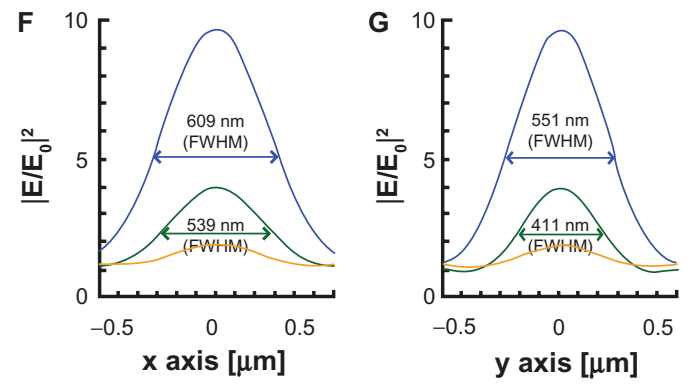

$\left|E / E_{0}\right|^{2}$

H

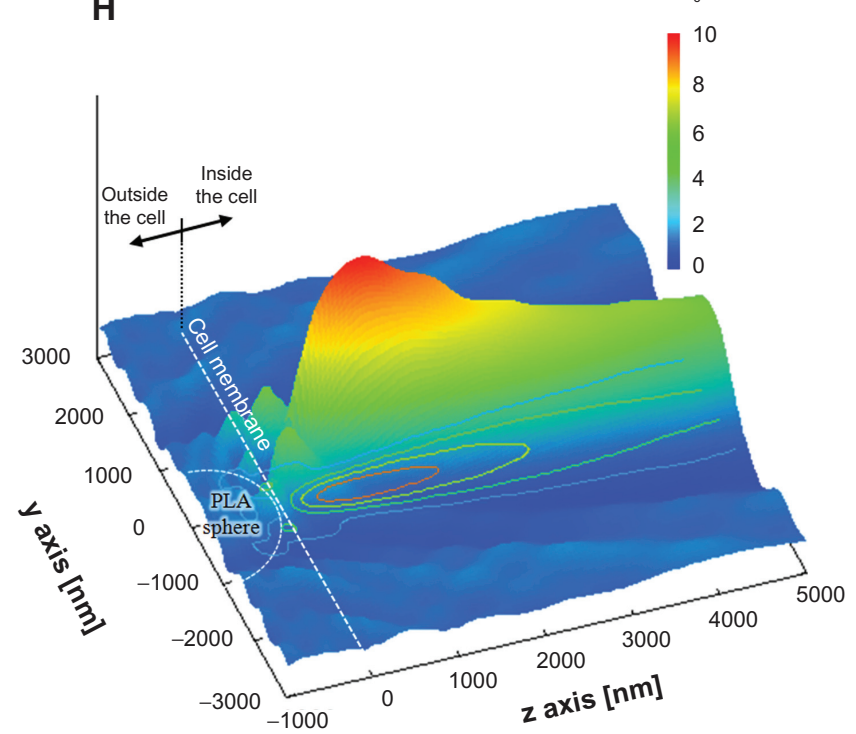

Figure 2 (A-D) Optical intensity distributions on the yz plane simulated by the three-dimensional finite-difference time-domain method for PLA spheres of different diameters: (A) $250 \mathrm{~nm}$, (B) $500 \mathrm{~nm}$, (C) $1000 \mathrm{~nm}$, and (D) $2000 \mathrm{~nm}$. A plane wave is illuminated to the sphere with the wave vector in the $z$ direction. The incident wave of $800 \mathrm{~nm}$ in wavelength is linearly polarized along the $\mathbf{x}$-axis. $(\mathbf{E}-\mathbf{G})$ Optical intensity distributions along $(\mathbf{E})$ the z-axis under the sphere, $(\mathbf{F})$ the $\mathbf{x}$-axis under the sphere on the peak intensity, shown as red horizontal line in $\mathbf{A}-\mathbf{D}$, and $(\mathbf{G})$ the $y$-axis under the sphere on the peak intensity. (H) Relative positions of focused far field, PLA sphere, and cell membrane on yz plane in the case of $2000 \mathrm{~nm}$ PLA sphere.

Note: Dashed circle and gray plane indicate the positions of the PLA sphere and the cell membrane, respectively.

Abbreviations: FWHM, Width at half maximum; PLA, polylactic acid. 


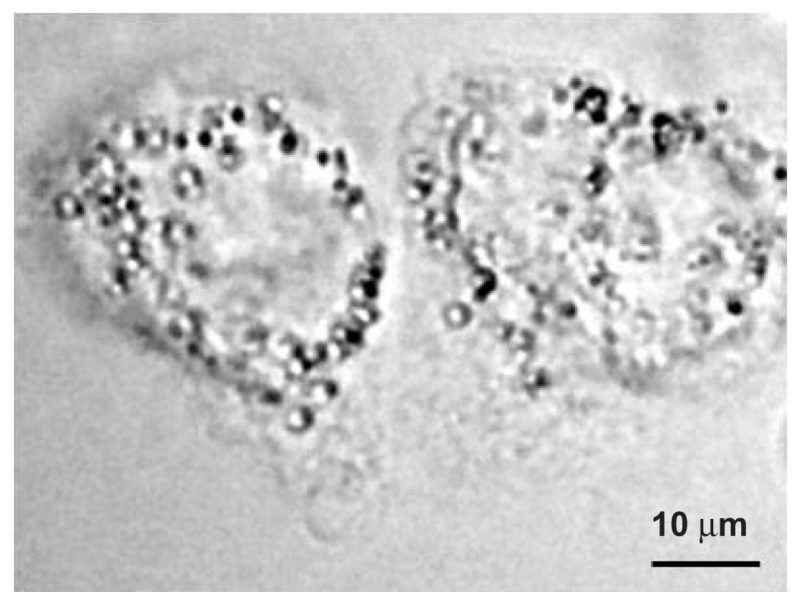

Figure 3 Phase contrast image of the A43I cells before laser illumination. Note: The polylactic acid spheres with a diameter of $2000 \mathrm{~nm}$ conjugated to the surface of the cells.

as a microlens and the focused intensity (far field) is kept high for distances longer than a few micrometers under the sphere, reaching a peak value at $870 \mathrm{~nm}$ under the sphere. The distance between the antibody-conjugated sphere and the cell membrane is several tens of nanometers. The long-focused zone of the sphere conjugated to the top surface of cell membrane is considered to be in the cytoplasm. Therefore, it is highly probable that the mechanism for perforation is not only due to the ablation of cell membrane.

Figure 5 shows the dependence of perforation efficiency and the survival rate on the laser fluence. The estimated peak intensity under the PLA sphere which was derived from Figure 2 is also shown in the figure. At the laser fluences lower than $0.8 \mathrm{~J} / \mathrm{cm}^{2}$, the perforation efficiency was lower than $10 \%$. The perforation efficiency was steeply increased at the laser fluences exceeding $0.88 \mathrm{~J} / \mathrm{cm}^{2}$, in which the corresponding peak laser intensity under the sphere is higher than $1.08 \times 10^{14} \mathrm{~W} / \mathrm{cm}^{2}$. In a previous study ${ }^{23}$ using PS sphere of $1000 \mathrm{~nm}$ in diameter, the steep increase in perforation efficiency was observed at $1.11 \times 10^{14} \mathrm{~W} / \mathrm{cm}^{2}$. These results suggest that the perforation is governed by the optical intensity under the sphere. At laser intensities of between $10^{13}$ and $10^{14} \mathrm{~W} / \mathrm{cm}^{2}$, nonlinear optical interactions with liquid and solid media, such as self phase modulation, selffocusing, multiphoton absorption, white-light continuum generation, laser-induced breakdown, laser ablation, are observed. ${ }^{27-29}$ The utilization of a fs laser at such intensities realizes dissection of axon, ${ }^{30}$ ablation of corneal stroma, ${ }^{31}$ and protein crystallization. ${ }^{32}$ It was reported that the peak pressure produced by fs laser-induced breakdown reaches
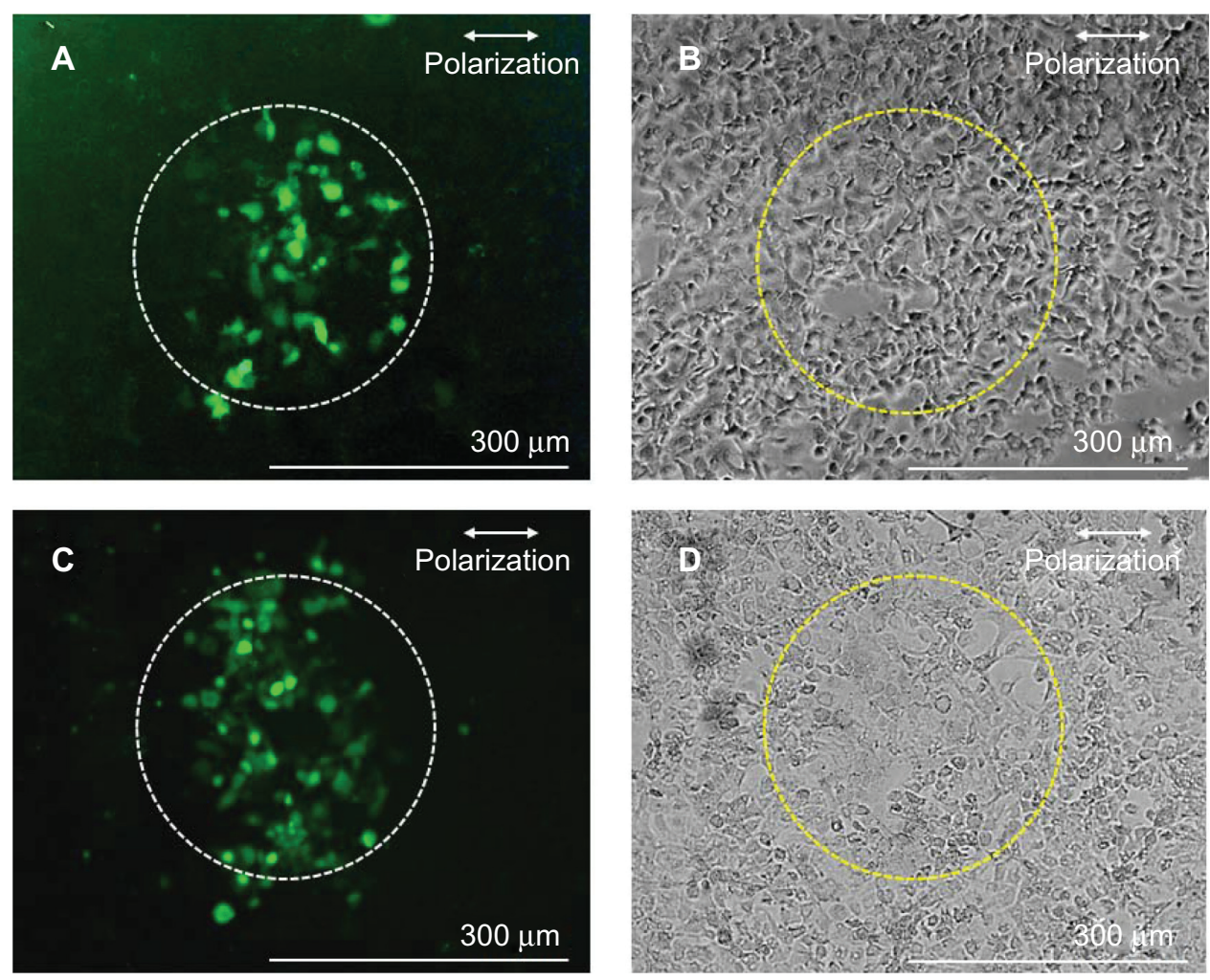

Figure 4 Fluorescence ( $\mathbf{A}$ and $\mathbf{C})$ and phase contrast (B and $\mathbf{D})$ images of A43I cells perforated by using antibody-conjugated polylactic acid spheres irradiated by a single fs laser pulse at $1.06 \mathrm{~J} / \mathrm{cm}^{2}$ in the presence of fluorescein isothiocyanate-dextran (A and $\mathbf{B}$ ) and Alexa Fluor-labeled small interfering RNA (C and $\mathbf{D}$ ). Note: Dashed circles (300 $\mu \mathrm{m}$ diameter) indicate the laser irradiated area.

Abbreviation: fs, femtosecond. 


\section{Focused peak intensity $\left(\mathrm{W} / \mathrm{cm}^{2}\right)$}

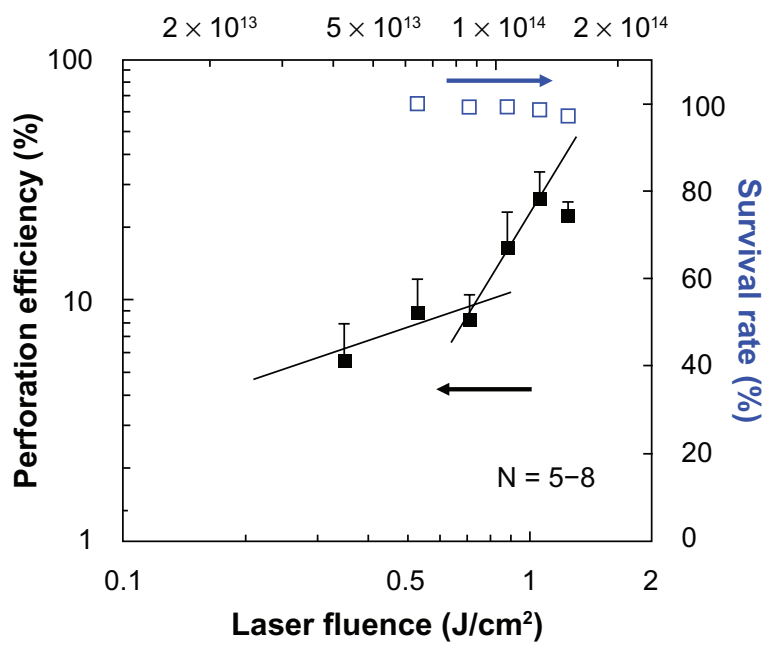

Figure 5 Dependence of perforation efficiency evaluated by using fluorescein isothiocyanate-dextran (closed squares) and survival rate (open squares) on the laser fluence.

Notes: A single shot of 80 -fs laser pulse was irradiated. The corresponding peak focused intensity under the polylactic acid sphere which was derived from Figure 2 is also shown on the top horizontal axis.

Abbreviation: fs, femtosecond.

several hundreds of $\mathrm{MPa} .{ }^{33}$ The peak pressure generated by the femtosecond laser-induced breakdown is much higher than that used for transfection by using a nanosecond laser-induced stress-wave. ${ }^{34,35}$ Although the membrane permeabilization depends not only on the peak pressure but also on the rise time and the impulse (temporal integration of pressure), ${ }^{36,37}$ it is highly probable that the femtosecond laser-induced cavitation bubble and the shock wave, as well as ablation of cell membrane, contributed to the cell membrane perforation with the peak intensity at $10^{14} \mathrm{~W} / \mathrm{cm}^{2}$, which is higher than the experimental breakdown threshold in water $\left(5.6 \times 10^{13} \mathrm{~W} / \mathrm{cm}^{2}\right) .{ }^{38}$ As can be seen in Figure 5, at laser fluences lower than $0.8 \mathrm{~J} / \mathrm{cm}^{2}$ a slope of 0.61 is obtained, while at laser fluences higher than $0.88 \mathrm{~J} / \mathrm{cm}^{2}$ the slope is 1.69. At laser fluences lower than $0.8 \mathrm{~J} / \mathrm{cm}^{2}$ with the slope of 0.61 , liquid water absorbs laser photons mainly as a linear absorption process. The absorption coefficient of liquid water at $800 \mathrm{~nm}$ is as small as $0.01 \mathrm{~cm}^{-1}$. In this low fluence domain, the laser heating process may govern the perforation process. While at the higher laser fluence domain, the laser absorption process is mainly due to the two-photon nonlinear optical process. Actually, the cornea ablation by fs laser is reported at approximately $1 \mathrm{~J} / \mathrm{cm}^{2} .{ }^{39} \mathrm{In}$ the present study, the high perforation rate is achieved by the two-photon absorption process. The survival rate was defined by the fraction of the cells in the illuminated area that stained with trypan blue. The survival rate slightly decreased with the increase of laser fluence, but it showed still higher than $95 \%$ at the highest laser fluence of $1.24 \mathrm{~J} / \mathrm{cm}^{2}\left(1.50 \times 10^{14} \mathrm{~W} / \mathrm{cm}^{2}\right.$ under the sphere). A slight decrease in the survival rate may be due to the excessive number of pores on the cell membrane for the cells which have too many spheres on the membrane.

Figure 6 shows a comparison of the average perforation efficiency for the four sets of the experimental conditions. The perforation efficiency by the 80 fs laser illumination with the PLA spheres conjugated to the cell membrane was significantly higher than the three other conditions. Under the condition of the cells without antibody (ie, 80 fs laser illumination without the conjugation of the PLA microspheres to the cell membrane), the perforation was not observed. The unbound microspheres were washed out before the laser illumination because of the lack of the antigen-antibody conjugation. For the cells illuminated with 80 fs laser without the PLA spheres, no perforation was observed. For the cells without the illumination of the 80 fs laser, no perforation was observed. Therefore, combination of the 80 fs laser illumination and the conjugation of the PLA spheres to the cells by antigen-antibody reactions were found necessary for the cell perforation. Based on the calculated optical intensity, the high focused intensity is kept nearly constant for distances longer than $1 \mu \mathrm{m}$. Therefore, PLA spheres that are deposited on the cell surface or loosely associated with unwashed cells also work for the perforation when the pulsed laser is illuminated. Considering in-vivo therapy, PLA

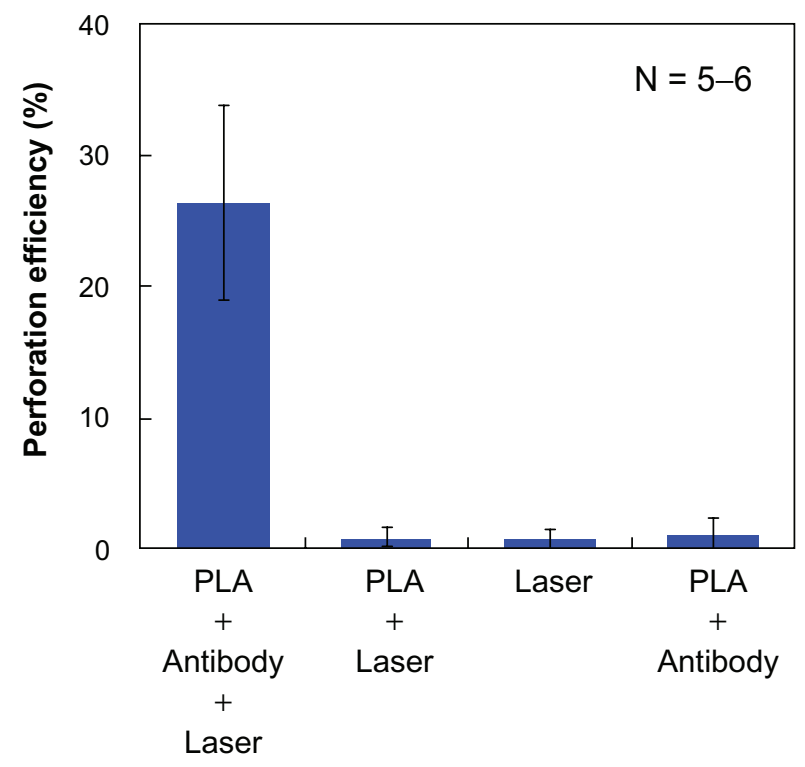

Figure 6 Average perforation efficiency under four different conditions. Note: A single $80 \mathrm{fs}$ laser pulse was irradiated at $1.06 \mathrm{~J} / \mathrm{cm}^{2}\left(1.29 \times 10^{14} \mathrm{~W} / \mathrm{cm}^{2}\right.$ under the PLA sphere).

Abbreviations: fs, femtosecond; PLA, polylactic acid. 
spheres are accumulated in the close vicinity of targeted cells by antigen-antibody reactions. Antibody works for the cell targeting, and then the laser illumination initiates the perforation. These results indicate that the present method can open a new avenue, which is considered an efficient adherent for the selective perforation of the cells which express the specific antigen on the cell membrane.

\section{Conclusion}

In this study, in vitro cell membrane perforation was demonstrated by using an antibody-conjugated biodegradable microsphere illuminated by a single $800 \mathrm{~nm}, 80 \mathrm{fs}$ laser pulse. FITC-dextran and siRNA were delivered to human epithelial carcinoma cells (A431 cells) by applying an $80 \mathrm{fs}$ laser pulse in the presence of antibody-conjugated PLA microspheres. This method has the advantage of high throughput, in which many cells can be treated by laser scanning method. The number of pulses for treatment area of $1 \mathrm{~cm}^{2}$ was 1415 , which can be achieved in 1.4 seconds at the laser repetition rate of $1 \mathrm{kHz}$. The enhancement factor obtainable under the sphere is dependent on the diameter and the refractive index of the sphere. Biodegradable polymers which have a higher refractive index than PLA, such as polylactic-co-glycolic acid, are potential candidates to be used in future study. The present method, using biodegradable microspheres, can open a new avenue for safer phototherapy and drug delivery in humans.

\section{Acknowledgments}

This work was supported in part by a Grand-in-Aid for Young Scientists (A) (23680058) by MEXT, Japan. The authors are grateful to Prof Minoru Obara for constructive comments on this paper.

\section{Disclosure}

The authors report no conflicts of interest in this work.

\section{References}

1. Oliveira MB, Mano JF. Polymer-based microparticles in tissue engineering and regenerative medicine. Biotech Prog. 2011;27(4):897-912.

2. Li W, Brown PK, Wang LV, Xia Y. Gold nanocages as contrast agents for photoacoustic imaging. Contrast Media Mol Imaging. 2011;6(5): 370-377.

3. Bardhan R, Lal S, Joshi A, Halas NJ. Theranostic nanoshells: from probe design to imaging and treatment of cancer. Acc Chem Res. 2011;44(10): 936-946.

4. Singh M, Chakrapani A, O'Hagan D. Nanoparticles and microparticles as vaccine-delivery systems. Expert Rev Vaccines. 2007;6(5): 797-808

5. Paulo CS, Pires das Neves R, Ferreira LS. Nanoparticles for intracellulartargeted drug delivery. Nanotechnology. 2011;22(49):494002/1-11.

6. Ai J, Biazar E, Jafarpour M, et al. Nanotoxicology and nanoparticle safety in biomedical designs. Int J Nanomedicine. 2011;6:1117-1127.
7. Pan Y, Neuss S, Leifert A, et al. Size-dependent cytotoxicity of gold nanoparticles. Small. 2007;3(11):1941-1949.

8. Chen YS, Hung YC, Liau I, Huang GS. Assessment of the in vivo toxicity of gold nanoparticles. Nanoscale Res Lett. 2009;4(8):858-864.

9. Hussain SM, Hess KL, Gearhart JM, Geiss KT, Schlagar JJ. In vitro toxicity of nanoparticles in BRL 3A rat liver cells. Toxicol In Vitro. 2005;19(7):975-983.

10. Warheit DB, Webb TR, Sayes CM, Colvin VL, Reed KL. Pulmonary instillation studies with nanoscale $\mathrm{TiO}_{2}$ rods and dots in rats: toxicity is not dependent upon particle size and surface area. Toxicol Sci. 2006; 91(1):227-236.

11. Yamawaki H, Iwai N. Mechanisms underlying nano-sized air-pollutionmediated progression of atherosclerosis - carbon black causes cytotoxic injury/inflammation and inhibits cell growth in vascular endothelial cells. Circ J. 2006;70:129-140.

12. Ulery BD, Nair LS, Laurencin CT. Biomedical application of biodegradable polymers. J Polym Sci B Polm Phys. 2011;49(12):832-864.

13. Tran VT, Benoît JP, Venier-Julienne MC. Why and how to prepare biodegradable, monodispersed, polymeric microparticles in the field of pharmacy? Int J Pharm. 2011;407(1-2):1-11.

14. Sato S, Ando T, Obara M. Optical fiber-based photomechanical gene transfer system for in vivo application. Opt Lett. 2011;36(23): 4545-4547.

15. Qian X, Peng X, Ansari DO, et al. In vivo tumor targeting and spectroscopic detection with surface-enhanced Raman nanoparticle tags. Nat Biotechnol. 2008;26(1):83-90.

16. Van de Broek B, Devoogdt N, D'Hollander A, et al. Specific cell targeting with nanobody conjugated branched gold nanoparticles for photothermal therapy. ACS Nano. 2011;5(6):4319-4328.

17. Pitsillides CM, Joe EK, Wei X, Anderson RR, Lin CP. Selective cell targeting with light-absorbing microparticles and nanoparticles. Biophys J. 2003;84(6):4023-4032.

18. Yao C, Qu X, Zhang Z, Hüttman G, Rahmanzadeh R. Influence of laser parameters on nanoparticle-induced membrane permeabilization. J Biomed Opt. 2009;14(5):054034/1-7.

19. Baumgart J, Humbert L, Lalonde BS, Lebrun JJ, Meunier M. Plasmonic enhanced fs-laser optoporation of human melanoma cells. Proc SPIE. 2011;7925:79250I/1-6.

20. Schomaker M, Baumgart J, Motekaitis D, et al. Mechanisms of gold nanoparticle mediated ultrashort laser cell membrane perforation. Proc SPIE. 2011;7925:79250F/1-6.

21. Baumgart J, Humbert L, Boulais E, Lachaine R, Lebrun JJ, Meunier M. Off-resonance plasmonic enhanced femtosecond laser optoporation and transfection of cancer cells. Biomaterials. 2012;33(7):2345-2350.

22. Chakravarty P, Qian W, El-Sayed MA, Prausnitz MR. Delivery of molecules into cells using carbon nanoparticles activated by femtosecond laser pulses. Nat Nanotechnol. 2010;5(8):607-611.

23. Terakawa M, Tanaka Y. Dielectric microsphere mediated transfection using a femtosecond laser. Opt Lett. 2011;36(15):2877-2879.

24. Sakai T, Tanaka Y, Nishizawa Y, Terakawa M, Obara M. Size parameter effect of dielectric small particle mediated nano-hole patterning on silicon wafer by femtosecond laser. Appl Phys A. 2010;99(1): 39-46.

25. Miller RA, Brady JM, Cutright DE. Degradation rates of oral resorbable implants (polylactates and polyglycolates): rate modification with changes in PLA/PGA copolymer ratios. J Biomed Mater Res. 1977;11:711-719.

26. Tanaka Y, Obara G, Zenidaka A, Terakawa M, Obara M. Femtosecond laser near-field nanoablation patterning using Mie resonance high dielectric constant particle with small size parameter. Appl Phys Lett. 2010;96:261103/1-3.

27. Brodeur A, Chin SL. Ultrafast white-light continuum generation and self-focusing in transparent condensed media. J Opt Soc Am B. 1999; 16(4):637-650.

28. Nagura C, Suda A, Kawano H, Obara M, Midorikawa K. Generation and characterization of ultrafast white-light continuum in condensed media. Appl Opt. 2002;41(18):3735-3742. 
29. Glezer EN, Schaffer CB, Nishimura N, Mazur E. Minimally disruptive laser-induced breakdown in water. Opt Lett. 1997;22(23):1817-1819.

30. Yanik MF, Cinar H, Cinar HN, Chisholm AD, Jin Y, Ben-Yakar A. Neurosurgery: functional regeneration after laser axotomy. Nature. 2004;432(7019):822.

31. Olivié G, Giguère D, Vidal F, et al. Wavelength dependence of femtosecond laser ablation threshold of corneal stroma. Opt Exp. 2008; 16(6):4121-4129.

32. Kashii M, Kitano H, Hosokawa Y, et al. Femtosecond laser processing of protein crystals in crystallization drop. Jpn JAppl Phys. 2005;44(27): L873-L875.

33. Vogel A, Noack J, Hüttman G, Paltauf G. Mechanisms of femtosecond laser nanosurgery of cells and tissues. Appl Phys B. 2005;81(8): 1015-1047.

34. Terakawa M, Sato S, Ashida H, et al. In vitro gene transfer to mammalian cells by the use of laser-induced stress waves: effects of stress wave parameters, ambient temperature, and cell type. J Biomed Opt. 2006;11(1):014026/1-7.
35. Aizawa K, Sato S, Terakawa M, et al. Accelerated adhesion of grafted skin by laser-induced stress wave-based gene transfer of hepatocyte growth factor. J Biomed Opt. 2009;14(6):064043/1-9.

36. Mulholland SE, Lee S, McAuliffe DJ, Doukas AG. Cell loading with laser-generated stress waves: the role of the stress gradient. Parm Res. 1999;16(4):514-518.

37. Kodama T, Hamblin MR, Doukas AG. Cytoplasmic molecular delivery with shock waves: importance of impulse. Biophys J. 2000;79(4): 1821-1832.

38. Schaffer CB, Nishimura N, Glezer EN, Kim AM, Mazur E. Dynamics of femtosecond laser-induced breakdown in water from femtoseconds to microseconds. Opt Exp. 2002;10(3):196-203.

39. Juhasz T, Loesel FH, Kurtz RM, Horvath C, Bille JF, Mourou G. Corneal refractive surgery with femtosecond lasers. IEEE J Sel Top Quantum Electron. 1999;5(4):902-910.
International Journal of Nanomedicine

\section{Publish your work in this journal}

The International Journal of Nanomedicine is an international, peerreviewed journal focusing on the application of nanotechnology in diagnostics, therapeutics, and drug delivery systems throughout the biomedical field. This journal is indexed on PubMed Central, MedLine, CAS, SciSearch $\AA$, Current Contents ${ }^{\circledR} /$ Clinical Medicine,

\section{Dovepress}

Journal Citation Reports/Science Edition, EMBase, Scopus and the Elsevier Bibliographic databases. The manuscript management system is completely online and includes a very quick and fair peer-review system, which is all easy to use. Visit http://www.dovepress.com/ testimonials.php to read real quotes from published authors. 